\title{
The effect of hyperoxia on mortality in critically ill patients: a systematic review and meta analysis
}

\author{
Yue-Nan $\mathrm{Ni}^{1+}$, Yan-Mei Wang ${ }^{2 \dagger}$, Bin-Miao Liang ${ }^{1 *}$ and Zong-An Liang ${ }^{1}$
}

\begin{abstract}
Background: Studies investigating the role of hyperoxia in critically ill patients have reported conflicting results. We did this analysis to reveal the effect of hyperoxia in the patients admitted to the intensive care unit (ICU).

Methods: Electronic databases were searched for all the studies exploring the role of hyperoxia in adult patients admitted to ICU. The primary outcome was mortality. Random-effect model was used for quantitative synthesis of the adjusted odds ratio (aOR).

Results: We identified 24 trials in our final analysis. Statistical heterogeneity was found between hyperoxia and normoxia groups in patients with mechanical ventilation $\left(I^{2}=92 \%, P<0.01\right)$, cardiac arrest $\left(I^{2}=63 \%, P=0.01\right)$, traumatic brain injury $\left(I^{2}=85 \%, P<0.01\right)$ and post cardiac surgery $\left(I^{2}=80 \%, P=0.03\right)$. Compared with normoxia, hyperoxia was associated with higher mortality in overall patients (OR 1.22, 95\% Cl 1.12 1.33), as well as in the subgroups of cardiac arrest (OR 1.30, 95\% Cl 1.08 1.57) and extracorporeal life support (ELS) (OR 1.44, 95\% Cl 1.03 2.02).

Conclusions: Hyperoxia would lead to higher mortality in critically ill patients especially in the patients with cardiac arrest and ELS.
\end{abstract}

Keywords: Hyperoxia, Mortality, Meta-analysis

\section{Background}

Oxygen supplement is a life saving treatment commonly used in the critically ill patients [1]. Excess oxygen delivery was reported to be a very common phenomenon, in which about $50 \%$ of the patients showed hyperoxemia and $4 \%$ in severe hyperoxemia [2].

Animal studies showed that hyperoxia is associated with adverse events such as histopathological injury, interstitial fibrosis, atelectasis, tracheobronchitis, alveolar protein leakage and infiltration by neutrophils [3]. Hyperoxia interacts with mechanical stretch to augment ventilator-induced lung injury [4]. Moreover, hyperoxia could also lead to a decline of cardiac output, [5] coronary blood flow and myocardial oxygen consumption, [6] and generate free radical-mediated damages in various

\footnotetext{
* Correspondence: liangbinmiao@163.com

${ }^{\dagger}$ Yue-Nan Ni and Yan-Mei Wang contributed equally to this work.

'Department of Respiratory and Critical Care, West China School of Medicine and West China Hospital, Sichuan University, No.37 Guoxue Alley, Chengdu 610041, China

Full list of author information is available at the end of the article
}

organs [7]. Studies in human demonstrated that hyperoxia could impair the responsiveness of host defense to infections [8]. Hyperoxia may affect a variety of patients' biological systems, such as antioxidant enzymes [9] and cytokine production [10] through excessive production of reactive oxygen species. Exaggerated apoptosis, in part through the death receptor-mediated signals, accelerates hyperoxia-induced acute lung injury [11]. However, clinical studies testing the relationship between hyperoxia and mortality in critically ill patients have yielded conflicting results. For example, in a study of 36,307 patients admitted to the intensive care units (ICU), no difference in mortality was noted between the patients exposed to hyperoxia and those who did not [12]. In contrast, Page et al. found that there was an association between hyperxia and increased mortality (adjusted odds ratio[aOR] 1.95, 95\% confidence interval[CI] 1.34-2.85) [13]. These conflicts were also seen in some specified diseases such as 1) patients with cardiac arrest, in which Elmer et al. showed a decreased survival (aOR 0.83, 95\% 
0.69-0.99, $P=0.04)$, [14] while Ihle et al. did not find any difference; [15] and 2) patients after traumatic brain injury(TBI), in which Asher et al. found a reduced mortality by hyperoxia while a contrary result was showed by Davis et al. [16, 17].

Although previous studies have performed the analysis of the relationship between hyperoxia and mortality, no solid conclusion has been drawn. As for several new studies in this topic being published recently, we conducted a systematic review and meta-analysis of all published trials aiming for identifying the roles of hyperoxia in the outcomes of patients in ICU.

\section{Methods}

\section{Search strategies}

Using the keywords of "hyperoxia" or "oxygenation target" or "hyperoxemia" or "oxygen saturation" or "arterial oxygen" and "critically ill" or "intensive care" or "mechanical ventilation", we conducted a comprehensive computer search in Pubmed, Embase, Medline, Cochrane Central Register of Controlled Trails (CENTRAL) and Information Sciences Institute (ISI) Web of Science from 1946 to December 2016 regardless of publication types or language. All the references listed in the identified articles were reviewed and manually searching for related articles was conducted in order to identify all eligible studies and achieve minimal publication bias.

\section{Inclusion and exclusion criteria}

The including criteria was as follows: 1) the subjects enrolled in each study included patients admitted to ICUs; 2) patients were divided into hyperoxia group and normoxia group; and 3) outcomes contained but not limited to mortality. We excluded studies if the patients were: 1 ) less than 18 years old; 2) chronic pulmonary disease; 3 ) acute lung injury or acute respiratory distress syndrome; and 4) in perioperative phase. Animal studies and studies published as reviews or case reports were also excluded.

\section{Study selection}

First of all, two independent authors screened the titles and abstracts. Secondly, after reviewing full texts, the authors included eligible studies according to the previously designed study inclusion criteria. A third author would deal with the disagreement between the above two authors by mutual consensus.

\section{Data extraction}

Recommended by Cochrane [18], two authors independently extracted and recorded desirable information of each enrolled study, which consisted of authors, publication year, study design, country, population, NCT No., primary disease, definition of hyperoxia and comparing group, outcome measures, and study results. For any missing data information, we made attempt to contact the corresponding authors by email for full original data. A third author was consulted when disagreement presence between the two authors.

\section{Statistical analysis}

Data was analyzed in Stata software by an independent statistician. At first, $X^{2}$ test was used to detect clinical, methodological and statistical heterogeneities. $P<0.1$ and $\mathrm{I}^{2}>50 \%$ was used to indicate significant heterogeneity. Mann-Whitney U-test was conducted to verify hypothesis and rendered statistical significance as a $\mathrm{Z}$-value and $P$-value $<0.05$. Forest plots are used to illustrate the results. Random-effects models were applied in the presence of statistical heterogeneity. The calculation of the effect size was based on the OR between hyperoxia and mortality. The sensitivity analysis was performed to substitute alternative decisions or ranges of values for decisions that were arbitrary or unclear.

\section{Results}

Initially 3173 records were identified, of which 3168 were extracted from electronic databases and 5 were from the reference lists review. (Figure 1) By screening the titles and abstracts, 3138 studies were discarded for duplication $(n=679)$, animal experiments $(n=1134)$ and non-adult patients $(n=1325)$. We searched the full-text articles for the remaining 35 studies, and eventually 24 trials were enrolled in our final analysis due to 10 studies not reporting related outcomes, and 1 did not designed as expected.

Hyperoxia defined as partial arterial pressure of oxygen $\left(\mathrm{PaO}_{2}\right)>487 \mathrm{~mm} \mathrm{Hg}(\mathrm{mmHg}), 341 \mathrm{mmHg}, 300 \mathrm{mmHg}$, $200 \mathrm{mmHg}, 156.7 \mathrm{mmHg}, 150 \mathrm{mmHg}, 120 \mathrm{mmHg}$ and $100 \mathrm{mmHg}$ was reported in $1,1,8,2,2,2,2$, and 3 studies, respectively. One study defined hyperoxia as $\mathrm{FiO}_{2}$ of 1.0, and the other two studies did not specify the definition of hyperoxia. As for the definition of normoxia, 12 studies did not report the details and the details of the other 12 studies have been listed in the Table 1.

\section{Study description}

All 24 studies compared the outcomes of hyperoxia with those of normoxia [12-17, 19-36]. The analysis of mortality included 22 studies [12-17, 19-34]. The other two studies were not included in the analysis because of limited number of studies in single primary disease. Details of each study were summarized in Table 1.

\section{Quality assessment}

For assessing the risk of bias in the enrolled studies, we used the Newcastle-Ottawa scale. A maximum of 9 points was assigned to each study: 4 for selection, 2 for comparability, and 3 for outcomes. A study with a final 


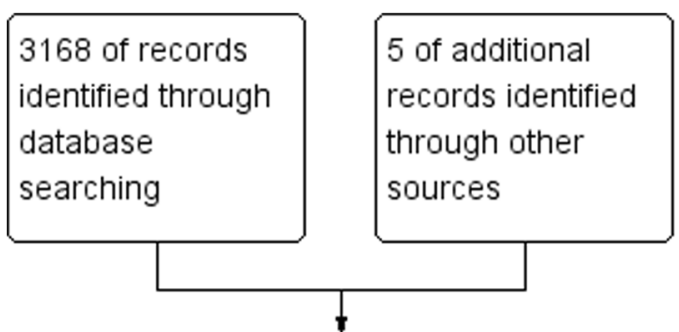

2494 of records after

duplicates removed

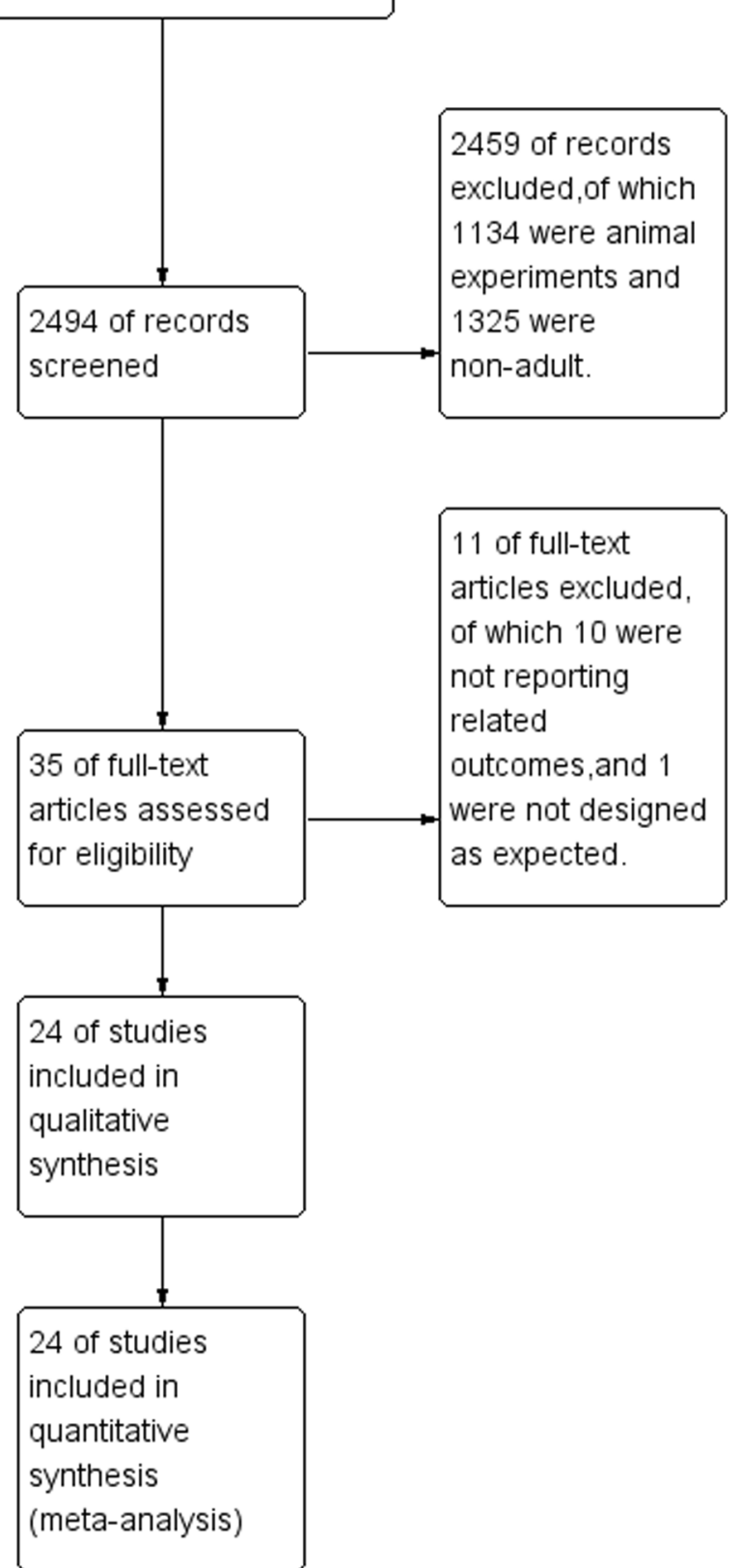

Fig. 1 Study flow 


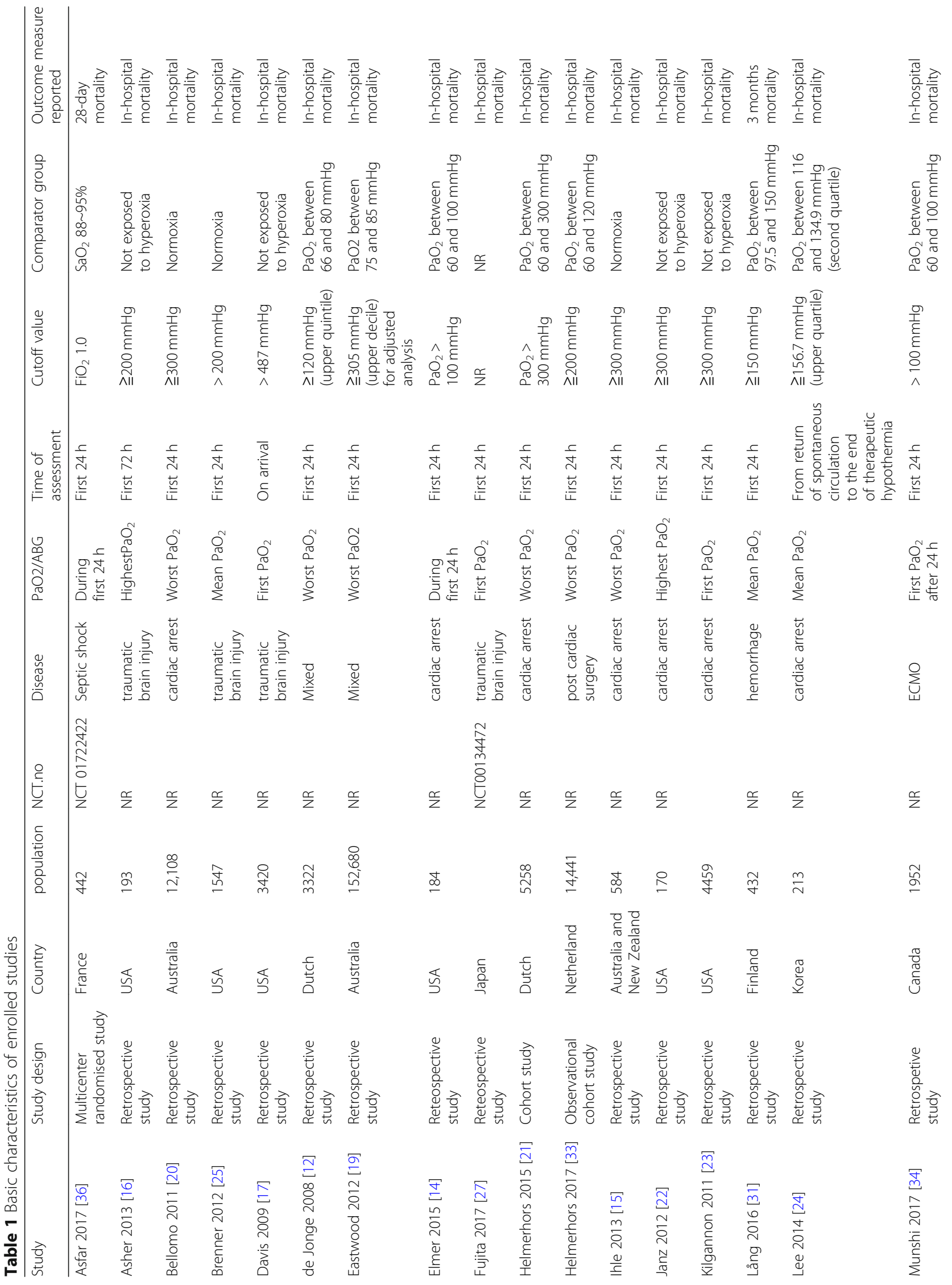




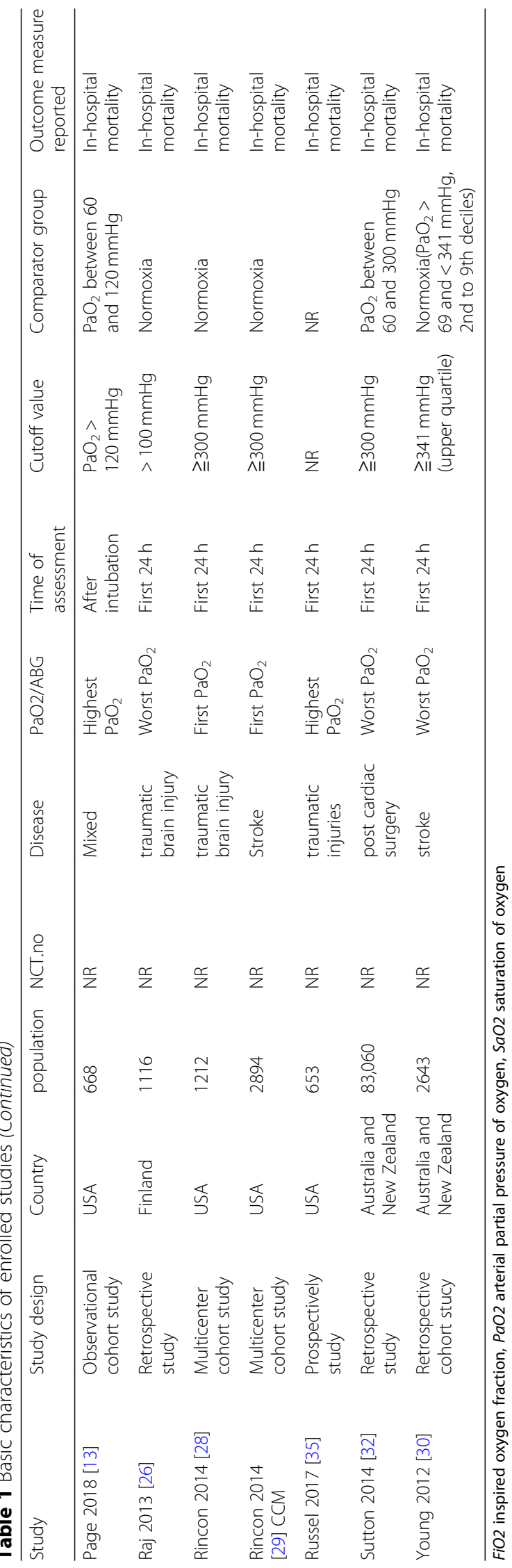


score $>6$ was regarded as high quality (Additional file 1). Among the 24 studies, one study [36] scored 8 points, 22 studies [12-17, 19-34] scored 7 points, and 1 study scored 6 points [35], which indicated a high risk of bias in the last study (Fig. 2). No studies were excluded for low quality or dubious decisions in the sensitivity analysis. The publication bias was not found (Fig. 3).

\section{Heterogeneity}

No significant statistical heterogeneity was found in mortality between hyperoxia and normoxia groups in patients with stroke and hemorrhage $\left(\mathrm{I}^{2}=48 \%, P=0.15\right)$ or extracorporeal life support (ELS) $\left(\mathrm{I}^{2}=35 \%, P=0.22\right)$. However, significant statistical heterogeneity existed in the comparison in patients with mechanical ventilation $\left(\mathrm{I}^{2}=92 \%, P<0.01\right)$, cardiac arrest $\left(\mathrm{I}^{2}=63 \%, P=0.01\right)$, TBI $\left(\mathrm{I}^{2}=85 \%, P<0.01\right)$ and post cardiac surgery $\left(\mathrm{I}^{2}=\right.$ $80 \%, P=0.03)$.

\section{Mortality}

Significant difference in the mortality was found between hyperoxia and normoxia groups in patients with cardiac arrest (OR 1.30, 95\% CI 1.08 1.57), ELS (OR 1.44, 95\% CI 1.03 2.02). However, hyperoxia did not

\begin{tabular}{|c|c|c|c|c|c|c|c|c|}
\hline & \multicolumn{4}{|l|}{ A Selection } & \multirow{2}{*}{$\begin{array}{l}\text { B Comparability } \\
\text { of cohorts }\end{array}$} & \multicolumn{3}{|l|}{ C Outcome } \\
\hline & $\begin{array}{l}\text { Represent- ativeness } \\
\text { of exposed cohort }\end{array}$ & $\begin{array}{l}\text { Selection of } \\
\text { non-exposed }\end{array}$ & $\begin{array}{l}\text { Ascertainment } \\
\text { of Exposure }\end{array}$ & $\begin{array}{l}\text { Outcome not } \\
\text { present at start }\end{array}$ & & $\begin{array}{l}\text { Assessment } \\
\text { of exposure }\end{array}$ & $\begin{array}{l}\text { Follow } \\
\text { up long e } \\
\text { nough? }\end{array}$ & $\begin{array}{l}\text { Adequacy } \\
\text { of follow } \\
\text { up }\end{array}$ \\
\hline Asher 2013 & th & t大 & th & 功 & & th & th & th \\
\hline Asfar 2017 & 故 & 茨 & 故 & 故 & 故为 & 故 & 公 & 论 \\
\hline Bellomo 2011 & 放 & 放 & 放 & 故 & & 放 & th & 虾 \\
\hline Brenner 2012 & th & H & th & $\Delta$ & & 放 & th & th \\
\hline Davis 2009 & th & 公 & th & 我 & & 公 & th & th \\
\hline de Jonge 2008 & 败 & 放 & th & th & & th & th & th \\
\hline Eastwood 2012 & th & th & th & 政 & & th & ț & th \\
\hline Elmer 2015 & 故 & 放 & 弐 & 故 & & 放 & 地 & th \\
\hline Fujita 2017 & 头 & 坖 & 为 & 故 & & 邹 & th & th \\
\hline Helmerhors 2015 & 故 & 幽 & 故 & 故 & & 故 & 放 & 论 \\
\hline Helmerhors 2017 & 放 & 幽 & 弐 & 放 & & 放 & 放 & 沛 \\
\hline Ihle 2013 & th & |t & th & | & & th & th & 斻 \\
\hline Janz 2012 & th & th & th & 故 & & th & th & th \\
\hline Kilgannon 2011 & 数 & 功 & th & $\not$ & & t & 站 & |t \\
\hline Lång 2016 & th & 幽 & 为 & 我 & & 舟 & th & 诂 \\
\hline Lee 2014 & 故 & 放 & 诂 & 故 & & 故 & th & 诂 \\
\hline Munshi 2017 & 故 & th & 弐 & 公 & & 类 & 项 & 幽 \\
\hline Page 2018 & 放 & 放 & 论 & 故 & & 放 & 放 & 虾 \\
\hline Raj 2013 & th & th & th & 功 & & th & th & th \\
\hline Rincon 2014 & t九 & 放 & th & $\Delta$ & & $\downarrow$ & th & th \\
\hline Rincon $2014 \mathrm{CCM}$ & 政 & t & 为 & 故 & & 象 & 类 & th \\
\hline Russell 2017 & 放 & 光 & 诂 & 政 & & 故 & & th \\
\hline Sutton 2014 & t & 放 & 弐 & 故 & & 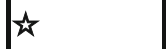 & th & th \\
\hline Young 2012 & 放 & th & 地 & $\not$ & & t & t & th \\
\hline
\end{tabular}

Fig. 2 Risk of bias 
Funnel plot with pseudo $95 \%$ confidence limits

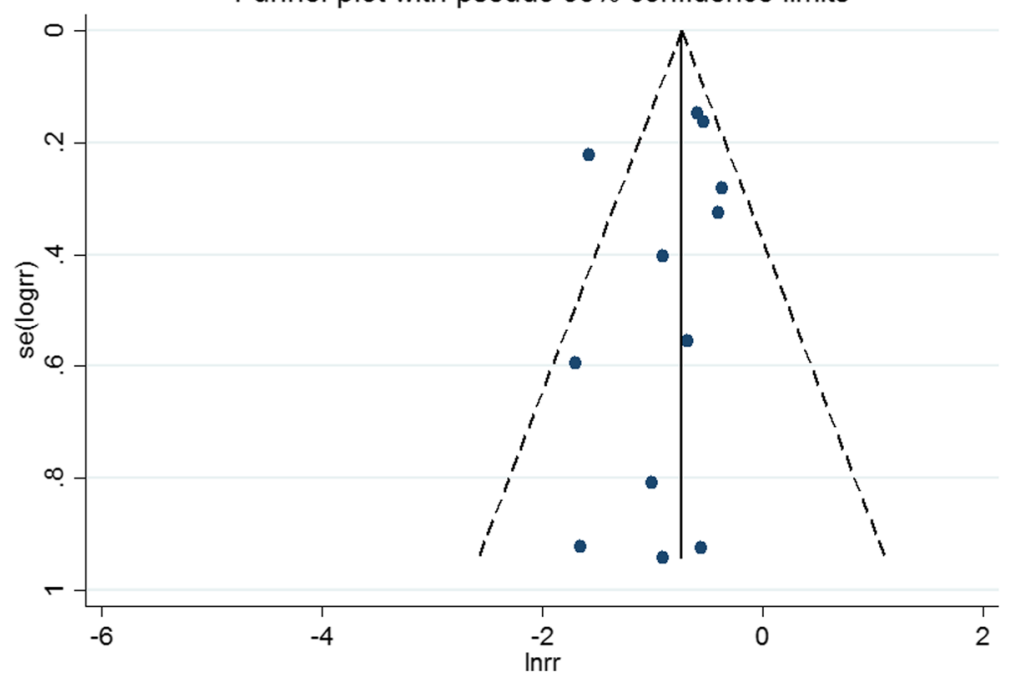

Fig. 3 Publication bias

contribute to higher mortality in patients with TBI (OR 1.23, 95\% CI 0.91 1.67), stroke(OR, 95\% CI), hemorrhage(OR 1.02, 95\% CI 0.76 1.36), post cardiac surgey(OR 1.06, 95\% CI $0.78 \sim 1.44)$ and mechanical ventilation(OR 1.23, 95\% CI 0.99 1.54). Over all, hyperoxia would increase the mortality of patients admitted to ICU(OR 1.22, 95\% CI 1.12 1.33). (Figure 4 and Additional files 2, 3, 4, 5, 6 and 7). In addition, 28-day mortality was similar in patients with septic shock between hyperoxia group and normoxia group (hazard ratio $1.27,95 \% \mathrm{CI} 0.94-1.72 ; P=0.12$ ) [36]. The same result was also found in the patients with severe traumatic injuries (OR 1.27, 95\% CI 0.72-2.25) [35].

\section{Discussion}

In our meta-analysis, we found that hyperoxia would increase the mortality of critically ill patients especially in the ones with cardiac arrest and ELS. In the patients with TBI, stroke and hemorrhage, post cardiac surgery and receiving mechanical ventilation due to mixed primary disease, hyperoxia did not increase mortality.

We found that hyperoxia would lead to adverse outcome in patients with cardiac arrest and ELS. Both of them included a process of reducing blood flow through the cardiac and unstable hemodynamics. The reasons for increased mortality by hyperoxia in patients with these diseases might be as follows. First of all, the exposing to hyperoxia would lead to the increase of reactive oxygen species, which would inhibit the vasodilators such as nitric oxide [37]. Study showed that vasodilator drugbased therapy is a superior solution to reduce mortality in hemodynamically unstable people such as acute myocardial infarction, heart failure or cardiac surgery [38]. Secondly, hyperoxia might increase vascular resistance and reduce cardiac output, coronary blood flow and myocardial $\mathrm{O}_{2}$ consumption [5, 6]. Reduced intravascular volume would result in cardiogenic shock, which is a life-threatening condition of circulatory failure [39]. Thirdly, pulmonary toxicity such as endothelial cell destruction, interstitial edema, and type I cell injury caused by the hyperoxia was noticed in animal experiment, and the resulting physiology responses included the increasing of pulmonary leukocyte and neutrophil accumulation, extravascular lung water and permeability surfacearea [40]. As a result, the total lung capacity decreased and ventilator-associated lung injury augmented $[3,40]$. Clinical study also showed that hyperoxia was associated with higher rate of ventilator associated pneumonia [41]. In addition, oxidative stress due to increased oxygen radical formation is one possible mechanism of ICU-required weakness [42]. Forthly, animal studies showed that high oxygen contraction would increase the oxidative stress and decrease antioxidant. These oxidants can react and damage the cellular macromolecules by virtue of the reactivity that leads to cell injury and necrosis. Oxidants are also mediators in damaging various organs and the organ failure is related to increased mortality [43]. It is reported that a high arterial oxygenation leads to myocardial reperfusion damage, with similar inflammatory consequences secondary to $\mathrm{O}_{2}$ free radical development.

However, in patients with TBI, stroke and hemorrhage, post cardiac surgery and received mechanical ventilation due to mixed primary disease, hyperoxia did not influence the mortality. The most possible explanation for this phenomenon is that the number of patients included in each subgroup was too small to find any significant differences in the mortality between the hyperoxia group and normoxia group. However, there are still 


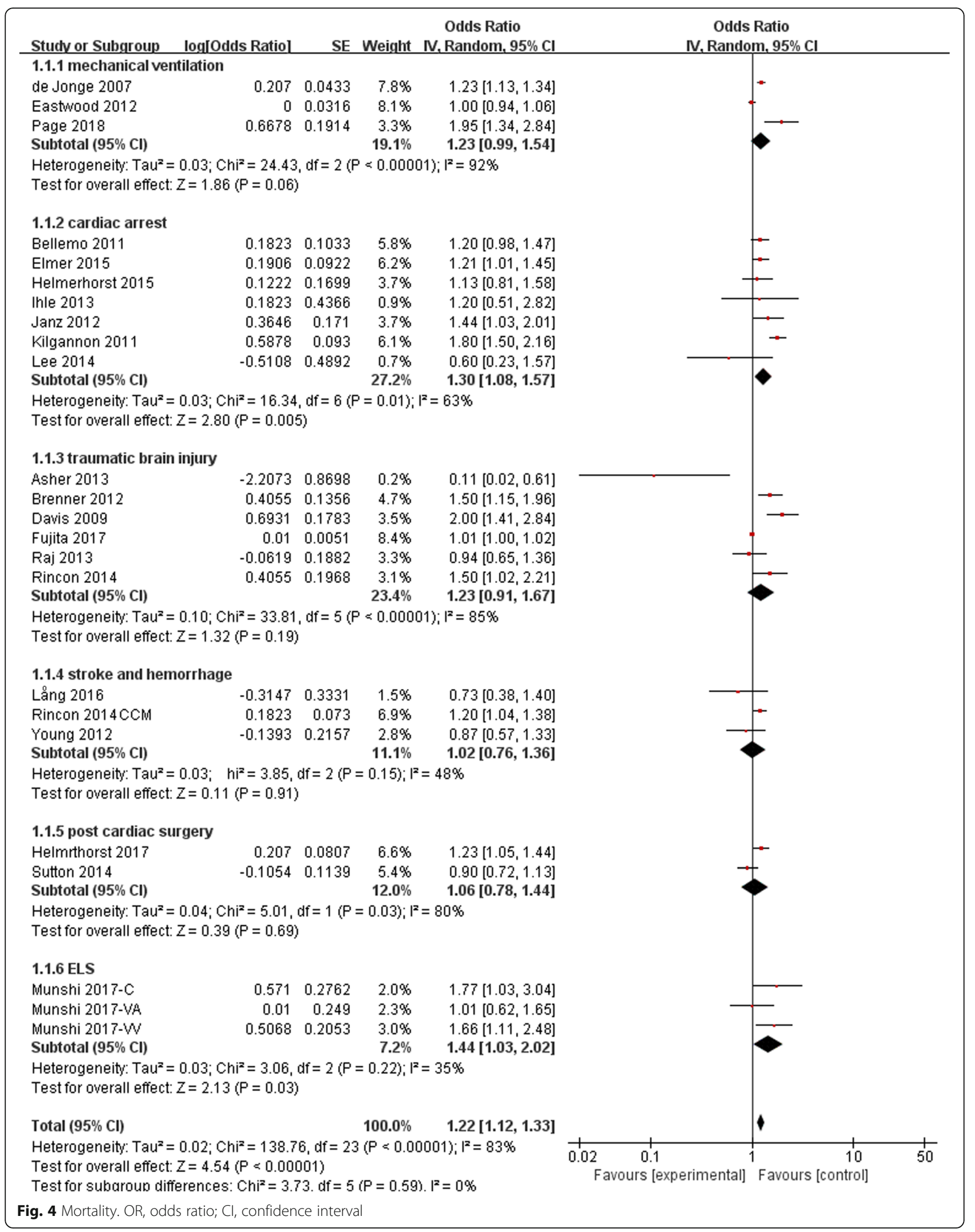


some assumptions. Traumatic injury and compartment syndrome may appear to be obvious applications for supplementary oxygen because an increased pressure of oxygen would help overcome the decline in perfusion. Several studies have showed the association between hyperoxia and poor outcome after severe TBI [44]. In TBI patients, oxygen delivery can be affected by a decline in cerebral blood flow. In addition, enhancement of brain edema and endothelial swelling after TBI has been demonstrated to decline the diffusion gradient for oxygen to the mitochondria [45]. There are both experimental and indirect clinical studies suggesting that after TBI aerobic metabolism in the brain goes down, [46] which leads to the mitochondrial dysfunction following TBI. Therefore, it is assumed that hyperoxic therapy could improve the oxygen content and thus raise the partial pressure of oxygen, which is the driving force for oxygen move to the mitochondria. This may promote aerobic metabolism in the brain, and thus improves overall outcomes [47]. The same effect also existed in patients with stroke and hemorrhage. There are increasing evidences illustrating that detrimental ischemia-related processes may be present although cerebral perfusion pressure and intracranial pressure levels are adequate [48]. The most effective way to improve hypoxia in brain tissue is to provide higher fraction of oxygen in inspired gas [49]. Therefore, although hyperoxia plays a role in lung injury and various organ failure, the advantages of hyperoxia might overweight the disadvantages and have no effect on the mortality. As for the patients with post cardiac surgery, although no significant difference was found in the mortality, a slight increase in the ICU and hospital stay may indicate a trend towards harm [32]. In addition, type 2 errors and mixed primary diseases may contribute to the result in patients with mechanical ventilation. In patients with septic shock, hyperoxia could lead to vascular contract and reduce oxygen uptake. Thus, hyperoxia could allow for hemodynamic stabilization during vasodilatory shock and do not increase the mortality [50]. Moreover, hyperoxia contributes to the improvement in tissue bed oxygenation in both peri-contusional and remote neuronal tissue, and more aerobic neural metabolic profiles [51]. This might be the reason that hyperoxia did not increase the mortality in patients with severe traumatic injurie.

We should notice that almost all the included studies in our analysis investigated the oxygenation target in the first $24 \mathrm{~h}$ rather than the whole phase in the ICU. According to the previous studies, hyperoxia was most common in the first $24 \mathrm{~h}$ in ICU. Meanwhile, the lung would get injuries when exposed to hyperoxia within 24 $\mathrm{h}$ [52]. In Kraft's study [53], they investigated the average oxygenation target during the whole ICU stay, which means the high $\mathrm{PaO} 2$ happened in the first $24 \mathrm{~h}$ might be offset by the low $\mathrm{PaO} 2$ value in the following days.

Moreover, clinical heterogeneity existed in our analysis, which might lead to difference in mortality between included studies. First of all, different definition of hyperoxia and normoxia. For example, in the Helmerhors' study, the definition of normoxia was $60<\mathrm{PaO} 2<$ $300 \mathrm{mmHg}$. However, in Elmer's study, the definition of hyperoxia was $\mathrm{PaO} 2>100 \mathrm{mmHg}$. Thus, part of patients, who should be included in the hyperoxia group in Elmers' study, were actually included in the normoxia group in the study of Helmerhors. Thus, the application of our study was limited. Secondly, we should notice that demographic information such as age, gender rate and severity of disease of patients were different. For example, the location of arrest was different in the 7 studies, which only included patients with cardiac arrest. The rate of patients' cardiac arrest happened outside hospital varied from 57 to $100 \%$, which would significantly influence the mortality of patients after cardiac arrest $[54,55]$.

There are some limitations of our analysis, which should be demonstrated. First of all, almost all the studies included in our analysis were retrospective studies. In this way, we could not figure out the relationship between the severity of the diseases and the level of arterial oxygen pressure. Second, clinical heterogeneity existed due to the mixed definition of hyperoxia, the oxygenation target in comparison group and the timing for measuring the outcome of patients. Third, in some subgroups, the number of patients was too small. Forth, significant statistical heterogeneity existed both in the overall and subgroup comparisons. Thus, the application of our conclusion is limited.

\section{Conclusions}

In conclusion, hyperoxia in patients admitted to the ICU would lead to higher mortality, which has been further confirmed in the patients with cardiac arrest and ELS.

\section{Additional files}

Additional file 1: Assessment of risk of bias and study quality. (DOC $18 \mathrm{~kb}$ )

Additional file 2: Figure S1. Mortality of patients with mechanical ventilation. OR, odds ratio; $\mathrm{Cl}$, confidence interval. (PNG $8 \mathrm{~kb}$ )

Additional file 3: Figure S2. Mortality of patients with cardiac arrest. $\mathrm{OR}$, odds ratio; $\mathrm{Cl}$, confidence interval. (PNG $9 \mathrm{~kb}$ )

Additional file 4: Figure S3. Mortality of patients with traumatic brain injury. OR, odds ratio; Cl, confidence interval. (PNG 9 kb)

Additional file 5: Figure S4. Mortality of patients with stroke hemorrhage. OR, odds ratio; $\mathrm{Cl}$, confidence interval. (PNG 8 kb)

Additional file 6: Figure S5. Mortality of patients with post cardiac surgery. OR, odds ratio; Cl, confidence interval. (PNG 7 kb)

Additional file 7: Figure S6. Mortality of patients with ELS. ELS, extracorporeal life support; OR, odds ratio; Cl, confidence interval. (PNG 8 kb) 


\section{Abbreviations}

CENTRAL: Cochrane Central Register of Controlled Trails; Cl: confidence interval; ELS: extracorporeal life support; ICU: intensive care unit; ISI: Information Sciences Institute; OR: odds ratio; SD: standard derivation; TBI: traumatic brain injury

\section{Acknowledgements}

We thank Professor Dongtao Lin (College of Foreign Languages, Sichuan University), who is specialized in biomedical writing and editing, for copyediting this manuscript.

\section{Funding}

The study design was supported by the Ministry of Science and Technology of the People's Republic of China(2013BAI09B09), literature search,the data analysis and writing was supported by the Ministry of Science and Technology of the People's Republic of China(2016YFC1304303).

\section{Availability of data and materials}

The data supporting our findings can be found by contacting with us (liangzatg@126.com).

\section{Authors' contributions}

Z-AL provided the conception of the study, Y-NN and Y-MW designed the study and drafted the manuscript; Y-MW conducted literature search and data analysis; Y-NN, B-ML and Z-AL revised the manuscript critically for important intellectual content; B-ML and Z-AL made the decision to submit the report for publication. All authors read and approved the final manuscript.

\section{Ethics approval and consent to participate}

Our study was approved by the Institutional Ethical Committee for Clinical and Biomedical Research of West China Hospital (Sichuan, China).

\section{Consent for publication}

Not applicable.

\section{Competing interests}

The authors declare that they have no competing interests.

\section{Publisher's Note}

Springer Nature remains neutral with regard to jurisdictional claims in published maps and institutional affiliations.

\section{Author details}

${ }^{1}$ Department of Respiratory and Critical Care, West China School of Medicine and West China Hospital, Sichuan University, No.37 Guoxue Alley, Chengdu 610041, China. ${ }^{2}$ Department of Respiratory Medicine, Sichuan Second Hospital of Traditional Chinese Medicine, Chengdu 610031, Sichuan, China.

\section{Received: 21 March 2018 Accepted: 11 February 2019}

Published online: 26 February 2019

\section{References}

1. Esteban A, Anzueto A, Alía I, Gordo F, Apezteguía C, Pálizas F, Cide D, Goldwaser R, Soto L, Bugedo G, et al. How is mechanical ventilation employed in the intensive care unit? An international utilization review. Am J Respir Crit Care Med. 2000;161(5):1450-8.

2. Helmerhorst HJ, Schultz MJ, van der Voort PH, Bosman RJ, Juffermans NP, de Wilde RB, van den Akker-van Marle ME, van Bodegom-Vos L, de Vries M, Eslami S, et al. Effectiveness and clinical outcomes of a two-step implementation of conservative oxygenation targets in critically ill patients: a before and after trial. Crit Care Med. 2016;44(3):554-63.

3. Altemeier WA, Sinclair SE. Hyperoxia in the intensive care unit: why more is not always better. Curr Opin Crit Care. 2007;13(1):73-8.

4. Sinclair SE, Altemeier WA, Matute-Bello G, Chi EY. Augmented lung injury due to interaction between hyperoxia and mechanical ventilation. Crit Care Med. 2004;32(12):2496-501.

5. Lodato RF. Decreased $\mathrm{O} 2$ consumption and cardiac output during normobaric hyperoxia in conscious dogs. J Appl Physiol (1985). 1989; 67(4):1551-9.
6. Farquhar $H$, Weatherall $M$, Wijesinghe $M$, Perrin $K$, Ranchord $A$, Simmonds M, Beasley R. Systematic review of studies of the effect of hyperoxia on coronary blood flow. Am Heart J. 2009;158(3):371-7.

7. Zwemer CF, Whitesall SE, D'Alecy LG. Hypoxic cardiopulmonary-cerebral resuscitation fails to improve neurological outcome following cardiac arrest in dogs. Resuscitation. 1995;29(3):225-36.

8. Tateda K, Deng JC, Moore TA, Newstead MW, Paine R 3rd, Kobayashi N, Yamaguchi K, Standiford TJ. Hyperoxia mediates acute lung injury and increased lethality in murine legionella pneumonia: the role of apoptosis. J Immunol. 2003;170(8):4209-16.

9. Bhandari V, Maulik N, Kresch M. Hyperoxia causes an increase in antioxidant enzyme activity in adult and fetal rat type II pneumocytes. Lung. 2000; 178(1):53-60.

10. Barazzone C, White CW. Mechanisms of cell injury and death in hyperoxia: role of cytokines and Bcl-2 family proteins. Am J Respir Cell Mol Biol. 2000; 22(5):517-9.

11. Barazzone C, Horowitz S, Donati YR, Rodriguez I, Piguet PF. Oxygen toxicity in mouse lung: pathways to cell death. Am J Respir Cell Mol Biol. 1998;19(4):573-81.

12. de Jonge $E$, Peelen $L$, Keijzers PJ, Joore $H$, de Lange $D$, van der Voort PH, Bosman RJ, de Waal RA, Wesselink R, de Keizer NF. Association between administered oxygen, arterial partial oxygen pressure and mortality in mechanically ventilated intensive care unit patients. Crit Care. 2008; 12(6):R156.

13. Page D, Ablordeppey E, Wessman BT, Mohr NM, Trzeciak S, Kollef MH, Roberts BW, Fuller BM. Emergency department hyperoxia is associated with increased mortality in mechanically ventilated patients: a cohort study. Crit Care. 2018;22(1):9.

14. Elmer J, Scutella M, Pullalarevu R, Wang B, Vaghasia N, Trzeciak S, RosarioRivera BL, Guyette FX, Rittenberger JC, Dezfulian C, Pittsburgh Post-Cardiac Arrest Service (PCAS). The association between hyperoxia and patient outcomes after cardiac arrest: analysis of a high-resolution database. Intensive Care Med. 2015:41(1):49-57.

15. Ihle JF, Bernard S, Bailey MJ, Pilcher DV, Smith K, Scheinkestel CD. Hyperoxia in the intensive care unit and outcome after out-of-hospital ventricular fibrillation cardiac arrest. Crit Care Resusc. 2013;15(3):186-90.

16. Asher SR, Curry P, Sharma D, Wang J, O'Keefe GE, Daniel-Johnson J, Vavilala MS. Survival advantage and $\mathrm{PaO} 2$ threshold in severe traumatic brain injury. J Neurosurg Anesthesiol. 2013;25(2):168-73.

17. Davis DP, Meade W, Sise MJ, Kennedy F, Simon F, Tominaga G, Steele J, Coimbra R. Both hypoxemia and extreme hyperoxemia may be detrimental in patients with severe traumatic brain injury. J Neurotrauma. 2009;26(12):2217-23.

18. Higgins JPT, Green S. Cochrane handbook for Systematic Reviews of Interventions Version 5.1.0 [updated March 2011]. The Cochrane Collaboration, 2011. Available from www.handbook.cochrane.org.

19. Eastwood G, Bellomo R, Bailey M, Taori G, Pilcher D, Young P, Beasley R. Arterial oxygen tension and mortality in mechanically ventilated patients. Intensive Care Med. 2012;38(1):91-8.

20. Bellomo R, Bailey M, Eastwood GM, Nichol A, Pilcher D, Hart GK, Reade MC, Egi M, Cooper DJ, Study of Oxygen in Critical Care (SOCC) Group. Arterial hyperoxia and in-hospital mortality after resuscitation from cardiac arrest. Crit Care. 2011;15(2):R90.

21. Helmerhorst HJ, Roos-Blom MJ, van Westerloo DJ, Abu-Hanna A, de Keizer $\mathrm{NF}$, de Jonge $\mathrm{E}$. Associations of arterial carbon dioxide and arterial oxygen concentrations with hospital mortality after resuscitation from cardiac arrest. Crit Care. 2015:19:348.

22. Janz DR, Hollenbeck RD, Pollock JS, McPherson JA, Rice TW. Hyperoxia is associated with increased mortality in patients treated with mild therapeutic hypothermia after sudden cardiac arrest. Crit Care Med. 2012; 40(12):3135-9.

23. Kilgannon JH, Jones AE, Parrillo JE, Dellinger RP, Milcarek B, Hunter K, Shapiro NI, Trzeciak S, Emergency Medicine Shock Research Network (EMShockNet) Investigators. Relationship between supranormal oxygen tension and outcome after resuscitation from cardiac arrest. Circulation. 2011:123(23):2717-22

24. Lee BK, Jeung KW, Lee HY, Lee SJ, Jung YH, Lee WK, Heo T, Min YI. Association between mean arterial blood gas tension and outcome in cardiac arrest patients treated with therapeutic hypothermia. Am J Emerg Med. 2014:32(1):55-60

25. Brenner M, Stein D, Hu P, Kufera J, Wooford M, Scalea T. Association between early hyperoxia and worse outcomes after traumatic brain injury. Arch Surg. 2012;147(11):1042-6. 
26. Raj R, Bendel S, Reinikainen M, Kivisaari R, Siironen J, Lång M, Skrifvars M. Hyperoxemia and long-term outcome after traumatic brain injury. Crit Care. 2013;17(4):R177.

27. Fujita M, Oda Y, Yamashita S, Kaneda K, Kaneko T, Suehiro E, Dohi K, Kuroda Y,Kobata H, Tsuruta R, Maekawa T. Early-stage hyperoxia is associated with favorable neurological outcomes and survival after severe traumatic brain injury: a post-hoc analysis of the brain hypothermia study. J Neurotrauma. 2017;34(8):1565-570

28. Rincon F, Kang J, Vibbert M, Urtecho J, Athar MK, Jallo J. Significance of arterial hyperoxia and relationship with case fatality in traumatic brain injury: a multicentre cohort study. J Neurol Neurosurg Psychiatry. 2014;85(7):799-805.

29. Rincon F, Kang J, Maltenfort M, Vibbert M, Urtecho J, Athar MK, Jallo J, Pineda CC, Tzeng D, McBride W, et al. Association between hyperoxia and mortality after stroke: a multicenter cohort study. Crit Care Med. 2014;42(2):387-96.

30. Young P, Beasley R, Bailey M, Bellomo R, Eastwood GM, Nichol A, Pilcher DV, Yunos NM, Egi M, Hart GK, et al. The association between early arterial oxygenation and mortality in ventilated patients with acute ischaemic stroke. Crit Care Resusc. 2012;14(1):14-9.

31. Lång $M$, Raj R, Skrifvars MB, Koivisto T, Lehto $H$, Kivisaari $R$, von Und Zu Fraunberg M, Reinikainen M, Bendel S. Early moderate Hyperoxemia does not predict outcome after aneurysmal subarachnoid hemorrhage. Neurosurgery. 2016;78(4):540-5.

32. Sutton AD, Bailey M, Bellomo R, Eastwood GM, Pilcher DV. The association between early arterial oxygenation in the ICU and mortality following cardiac surgery. Anaesth Intensive Care. 2014;42(6):730-5.

33. Helmerhorst HJ, Arts DL, Schultz MJ, van der Voort PH, Abu-Hanna A, de Jonge $E$, van Westerloo DJ. Metrics of arterial Hyperoxia and associated outcomes in critical care. Crit Care Med. 2017:45(2):187-95.

34. Munshi L, Kiss A, Cypel M, Keshavjee S, Ferguson ND, Fan E. Oxygen thresholds and mortality during extracorporeal life support in adult patients. Crit Care Med. 2017:45(12):1997-2005

35. Russell DW, Janz DR, Emerson WL, May AK, Bernard GR, Zhao Z, Koyama T, Ware LB. Early exposure to hyperoxia and mortality in critically ill patients with severe traumatic injuries. BMC Pulm Med. 2017;17(1):29.

36. Asfar $P$, Schortgen F, Boisramé-Helms J, Charpentier J, Guérot E, Megarbane B, Grimaldi D, Grelon F, Anguel N, Lasocki S, et al. Hyperoxia and hypertonic saline in patients with septic shock (HYPERS2S): a two-by-two factorial, multicentre, randomised, clinical trial. Lancet Respir Med. 2017:5(3):180-90.

37. Zhilyaev SY, Moskvin AN, Platonova TF, Gutsaeva DR, Churilina IV, Demchenko IT. Hyperoxic vasoconstriction in the brain is mediated by inactivation of nitric oxide by superoxide anions. Neurosci Behav Physiol. 2003;33(8):783-7.

38. Schumann J, Henrich EC, Strobl H, Prondzinsky R, Weiche S, Thiele H, Werdan K, Frantz S, Unverzagt S. Inotropic agents and vasodilator strategies for the treatment of cardiogenic shock or low cardiac output syndrome. Cochrane Database Syst Rev. 2018;1:CD009669.

39. De Backer D, Biston P, Devriendt J, Madl C, Chochrad D, Aldecoa C, Brasseur A, Defrance P, Gottignies P, Vincent JL, SOAP II Investigators. Comparison of dopamine and norepinephrine in the treatment of shock. N Engl J Med. 2010;362(9):779-89.

40. Crapo JD, Hayatdavoudi G, Knapp MJ, Fracica PJ, Wolfe WG, Piantadosi CA. Progressive alveolar septal injury in primates exposed to 60\% oxygen for 14 days. Am J Phys. 1994;267(6 Pt 1):L797-806.

41. Six S, Jaffal K, Ledoux G, Jaillette E, Wallet F, Nseir S. Hyperoxemia as a risk factor for ventilator-associated pneumonia. Crit Care. 2016;20(1):195.

42. Kress JP, Hall JB. ICU-acquired weakness and recovery from critical illness. NEngl J Med. 2014;371(3):287-8.

43. Marshall JC, Cook DJ, Christou NV, Bernard GR, Sprung CL, Sibbald WJ. Multiple organ dysfunction score: a reliable descriptor of a complex clinical outcome. Crit Care Med. 1995;23(10):1638-52.

44. Oddo M, Levine JM, Mackenzie L, Frangos S, Feihl F, Kasner SE, Katsnelson M, Pukenas B, Macmurtrie E, Maloney-Wilensky E, et al. Brain hypoxia is associated with short-term outcome after severe traumatic brain injury independently of intracranial hypertension and low cerebral perfusion pressure. Neurosurgery. 2011;69(5):1037-45 discussion 1045

45. Vespa PM, McArthur D, O'Phelan K, Glenn T, Etchepare M, Kelly D, Bergsneider M, Martin NA, Hovda DA. Persistently low extracellular glucose correlates with poor outcome 6 months after human traumatic brain injury despite a lack of increased lactate: a microdialysis study. J Cereb Blood Flow Metab. 2003;23(7):865-77.
46. Siggaard-Andersen O, Fogh-Andersen N, Gøthgen $I H$, Larsen VH. Oxygen status of arterial and mixed venous blood. Crit Care Med. 1995; 23(7):1284-93

47. Adamides AA, Winter CD, Lewis PM, Cooper DJ, Kossmann T, Rosenfeld JV. Current controversies in the management of patients with severe traumatic brain injury. ANZ J Surg. 2006;76(3):163-74.

48. Chen HI, Stiefel MF, Oddo M, Milby AH, Maloney-Wilensky E, Frangos S, Levine JM, Kofke WA, LeRoux PD. Detection of cerebral compromise with multimodality monitoring in patients with subarachnoid hemorrhage. Neurosurgery. 2011;69(1):53-63 discussion 63.

49. Bohman LE, Pisapia JM, Sanborn MR, Frangos S, Lin E, Kumar M, Park S, Kofke WA, Stiefel MF, LeRoux PD, et al. Response of brain oxygen to therapy correlates with long-term outcome after subarachnoid hemorrhage. Neurocrit Care. 2013;19(3):320-8.

50. Bitterman H. Bench-to-bedside review: oxygen as a drug. Crit Care. 2009; 13(1):205.

51. Tolias CM, Reinert M, Seiler R, Gilman C, Scharf A, Bullock MR. Normobaric hyperoxia--induced improvement in cerebral metabolism and reduction in intracranial pressure in patients with severe head injury: a prospective historical cohort-matched study. J Neurosurg. 2004;101(3):435-44.

52. Sackner MA, Landa J, Hirsch J, Zapata A. Pulmonary effects of oxygen breathing. A 6-hour study in normal men. Ann Intern Med. 1975;82(1):40-3.

53. Kraft F, Andel H, Gamper J, Markstaller K, Ullrich R, Klein KU. Incidence of hyperoxia and related in-hospital mortality in critically ill patients: a retrospective data analysis. Acta Anaesthesiol Scand. 2018;62(3):347-56.

54. Rea TD, Eisenberg MS, Becker LJ, Murray JA, Hearne T. Temporal trends in sudden cardiac arrest: a 25-year emergency medical services perspective. Circulation. 2003;107(22):2780-5.

55. Goldberger ZD, Chan PS, Berg RA, Kronick SL, Cooke CR, Lu M, Banerjee M, Hayward RA, Krumholz HM, Nallamothu BK, American Heart Association Get With The Guidelines-Resuscitation (formerly National Registry of Cardiopulmonary Resuscitation) Investigators. Duration of resuscitation efforts and survival after in-hospital cardiac arrest: an observational study. Lancet. 2012;380(9852):1473-81.

Ready to submit your research? Choose BMC and benefit from

- fast, convenient online submission

- thorough peer review by experienced researchers in your field

- rapid publication on acceptance

- support for research data, including large and complex data types

- gold Open Access which fosters wider collaboration and increased citations

- maximum visibility for your research: over $100 \mathrm{M}$ website views per year

At $\mathrm{BMC}$, research is always in progress.

Learn more biomedcentral.com/submission 